\title{
NUTRICOSMÉTICOS: UM NOVO CONCEITO PARA SAÚDE E SEUS BENEFÍCIOS NO PROCESSO DE ENVELHECIMENTO
}

\section{NUTRICOSMETICS: A NEW CONCEPT FOR HEALTH AND ITS BENEFITS IN THE AGING PROCESS}

\author{
Aline Cervino Peleteiro ${ }^{1}$ \\ Kamilla Alcantara Fernandes de Jesus ${ }^{2}$ \\ Simara Neto Ferreira ${ }^{3}$ \\ Juliana Lima Gomes Rodrigues 4
}

RESUMO: Os nutricosméticos são conhecidos como pílulas da beleza, porque consistem em suplementos orais e possuem a finalidade de nutrir o organismo com concentrados de vitaminas e outros ativos, sobretudo, antioxidantes, de modo a tratar a pele "de dentro para fora”. O objetivo deste estudo é abordar a ação dos nutricosméticos no combate ao envelhecimento cutâneo causado pelo estresse oxidativo. Trata-se de uma revisão bibliográfica do tipo exploratória e de natureza qualitativa. Foi realizado um levantamento bibliográfico a partir das bases de dados: Biblioteca Virtual em Saúde (BVS), Medical Literature Analysis and Retrieval System On-line (MEDLINE) e Literatura LatinoAmericana e do Caribe em Ciências da Saúde (LILACS), além da Scientific Electronic Library Online (SciELO). A pesquisa na literatura resultou em um total de 85 artigos. Destes is foram excluídos por apresentarem duplicidade nas buscas, 45 foram excluídos por não atenderem os critérios de inclusão, restando 25 artigos que abordaram ação dos nutricosméticos no combate ao envelhecimento cutâneo causado pelo estresse oxidativo nesta revisão de literatura. Como achados mais relevantes este estudo apontou que que os Nutricosméticos possuem ação principalmente antioxidante e são capazes de prevenir a ação dos radicais livres no processo de envelhecimento cutâneo, bem como amenizam os processos oxidativos e reduzem os danos causados nas células. Dessa forma, o uso dos nutricosméticos pode trazer benefícios como a melhora dos aspectos da pele e auxiliar nos tratamentos das disfunções da pele e tecidos em desordem.

Palavras-chaves: Nutricosméticos. Envelhecimento. Envelhecimento Cutâneo.

ABSTRACT: Nutricosmetics are known as beauty pills, because they consist of oral supplements and have the purpose of nourishing the body with concentrated vitamins and

\footnotetext{
${ }^{r}$ Discente de farmácia Universidade Salvador.

${ }^{2}$ Discente de farmácia Universidade Salvador.

${ }^{3}$ Discente de farmácia Universidade Salvador.

4 Docente de farmácia Universidade Salvador.
} 
other actives, especially antioxidants, in order to treat the skin "from the inside out". The aim of this study is to address the action of nutricosmetics in combating skin aging caused by oxidative stress. This is an exploratory and qualitative bibliographic review. A bibliographic survey was carried out using the following databases: Virtual Health Library (VHL), Online Medical Literature Analysis and Retrieval System (MEDLINE) and Latin American and Caribbean Health Sciences Literature (LILACS), in addition to Scientific Electronic Library Online (SciELO). The literature search resulted in a total of 85 articles. Of these 15 were excluded for presenting duplicity in the searches, 45 were excluded for not meeting the inclusion criteria, leaving 25 articles that addressed the action of nutricosmetics in combating skin aging caused by oxidative stress in this literature review. As the most relevant findings, this study pointed out that Nutricosmetics have antioxidant action and are able to prevent the action of free radicals in the skin aging process, as well as soften the oxidative processes and reduce the damage caused to cells. It is possible to conclude that the use of nutricosmetics brings benefits such as the improvement of skin aspects and helps in the treatment of skin disorders and tissue disorders.

Keywords: Nutricosmetics. Aging. Skin Aging.

\section{INTRODUÇÃO}

O envelhecimento é um processo que engloba a união de transformações na sua dimensão biológica que sofre influência de fatores intrínsecos e extrínsecos. Os tecidos, gradualmente, sofrem mudanças observadas na pele, unhas e cabelos pela atrofia, enrugamento, lassidão, e outras transformações. Nessas alterações estão inclusos os fatores de ordem biopsicossocial na vida dos indivíduos e que podem refletir na autoestima, sobretudo, de algumas mulheres que julgam que a boa aparência e jovialidade da pele consistem em características indispensáveis para se manterem jovens e bonitas (ANUCIATO, 20II).

O envelhecimento consiste em um fenômeno fisiológico que acomete qualquer tipo de tecido, no qual a fibra de colágeno, componente do tecido conjuntivo, se torna mais rígida com a idade (CARVALHO e SILVA, 20II). A elastina, outro componente do mesmo tecido, vai perdendo a sua elasticidade natural por causa da redução do número de fibras elásticas e de outros componentes do tecido conjuntivo. Esse processo, favorece a diminuição de colágeno e queratina, o que culmina em pele seca, surgimento de rugas, queda de cabelo, unhas frágeis e redução do crescimento de cabelos e unhas (CRUZ et al., 2020). 
Agentes externos, tais quais: tabaco, álcool, alimentação inadequada, exposição solar desprotegida e descontrolada, colaboram para o fotoenvelhecimento, decorrente da exposição a fatores ambientais. A ciência vem estudando agentes importantes na promoção da longevidade humana, resultando em "pílulas da beleza", conhecidas como nutricosméticos, os quais são suplementos orais com a função de nutrição do organismo com concentrados que são capazes de tratar a pele, cabelo e unhas de dentro para fora (DIAS et al., 20II).

Os nutricosméticos são conhecidos como pílulas da beleza, porque consistem em uma combinação entre alimentos, cosméticos e medicamentos que colaboram para a manutenção de um organismo saudável, consistindo na última tendência da indústria da beleza. Esses produtos trazem consigo a pretensão de proteger, além de tratar a pele internamente e externamente, amplificando o tratamento estético (RUIZ, 2012).

Os nutricosméticos podem ser conceituados como suplementos nutricionais porque contém em sua composição vitaminas, aminoácidos, proteínas e/ou ativos botânicos e antioxidantes, o que justifica sua prescrição para o retardo do envelhecimento, promovendo a melhora da firmeza cutânea. O surgimento desses suplementos no mercado é consequência da convergência entre as indústrias de cosméticos e de alimentos. Esse movimento de convergência tem acontecido em diversas indústrias, de modo a atender às novas demandas dos consumidores (KING, 20II).

Ademais, os nutricosméticos são produtos alimentares que exercem ação cosmética, unindo nutrição à saúde do corpo e da pele. Essas substâncias têm como objetivo potencializar os resultados para o tratamento da pele em associação com os produtos cosméticos de uso tópico (PINHEIRO; SILVA; PESSOA, 2018).

Segundo Peixoto e colaboradores (2013), os nutricosméticos também tem ação no equilíbrio da deficiência nutricional do indivíduo, como por exemplo: o déficit de proteínas, vitaminas ou minerais, que podem combater ainda o excesso de radicais livres produzidos pelo organismo. Contudo, a utilização destes produtos demanda racionalidade e cuidados, visto que não devem ser considerados como substituintes dos nutrientes e devem ser utilizados com a prévia orientação de um profissional habilitado. Em vista de 
que produtos deste caráter consistem em complementos alimentares e passíveis de causarem efeitos colaterais, a sua administração deve ocorrer de modo racional.

O presente estudo justifica-se pela percepção de que os nutricosméticos tratam-se de uma nova tendência capaz de melhorar a integridade e a beleza da pele. A utilização desses produtos visa proteger e tratar a pele de dentro para fora, colaborando para que o tratamento estético seja mais completo porque agem no equilíbrio do déficit nutricional, como a falta de proteínas, vitaminas ou minerais, bem como combatem o excesso de radicais livres no organismo.

São produtos que surgem como inovação no mundo da beleza, trazendo esses novos benefícios em fórmula de cápsulas e comprimidos. Embora existam benefícios, podem oferecer também riscos importantes, por isso, deve ser levada em consideração as características individuais do usuário, bem como possíveis comorbidades. O consumo em excesso pode ocasionar Hipervitaminose, discromia da pele, entre outros efeitos nãodesejados. Deste modo, o uso destes suplementos demanda cuidados e deve ser realizado com a indicação de um profissional com formação na área médica ou nutricional, tornando-se importante realização de produções cientificas que abordem a temática no intuito de esclarecer os efeitos dos nutricosméticos e promover um uso seguro e racional. O objetivo deste estudo é abordar a ação dos nutricosméticos no combate ao envelhecimento cutâneo causado pelo estresse oxidativo.

\section{METODOLOGIA}

Trata-se de uma revisão bibliográfica do tipo exploratória e de natureza qualitativa. Foi realizado um levantamento bibliográfico com a finalidade de pesquisar o conhecimento produzido sobre o tema deste estudo. A produção cientifica foi coletada nas bases de dados: Biblioteca Virtual em Saúde (BVS), Medical Literature Analysis and Retrieval System On-line (MEDLINE) e Literatura Latino-Americana e do Caribe em Ciências da Saúde (LILACS), além da Scientific Electronic Library Online (SciELO).

Foram utilizadas as seguintes palavras-chaves:Nutricosméticos, Envelhecimento, Envelhecimento Cutâneo. Os critérios de inclusão para seleção dos artigos foram: artigos na íntegra, que contenham no resumo alguma evidência do tema, pesquisado nos idiomas 
português e inglês, publicados no período entre 2011 a 2021. Foram excluídas produções duplicadas e aquelas que não tratarem de informações sobre a temática, artigos que não sejam disponibilizados de forma completa online; artigos que não se enquadrem nos critérios de inclusão.

\section{RESULTADOS E DISCUSSÃO}

A pesquisa na literatura resultou em um total de 85 artigos. Destes, is foram excluídos por apresentarem duplicidade nas buscas, 45 foram excluídos por não atenderem os critérios de inclusão, restando 25 artigos que abordaram ação dos nutricosméticos no combate ao envelhecimento cutâneo causado pelo estresse oxidativo nesta revisão de literatura. No quadro I, estão elencados 12 estudos que apresentaram os benefícios dos nutricosméticos.

Quadro I- Estudos que avaliaram os benefícios dos nutricosméticos.

\begin{tabular}{|c|c|c|c|}
\hline TÍTULO/ANO & OBJETIVO & METODOLOGIA & $\begin{array}{l}\text { PRINCIPAIS } \\
\text { RESULTADOS }\end{array}$ \\
\hline $\begin{array}{l}\text { FIGUEIREDO } \\
(2011)\end{array}$ & $\begin{array}{l}\text { Avaliar os efeitos da } \\
\text { suplementação de } \\
\text { peptídeos de } \\
\text { colágeno }\end{array}$ & Revisão de literatura. & $\begin{array}{l}\text { A suplementação } \\
\text { alimentar diária é um } \\
\text { grande aliado para a } \\
\text { saúde e beleza dos } \\
\text { indivíduos, garantindo } \\
\text { com o passar dos anos a } \\
\text { reposição de peptídeos } \\
\text { de colágeno para } \\
\text { manutenção das } \\
\text { funções estruturais da } \\
\text { pele, cabelo e unhas, } \\
\text { além do aporte de } \\
\text { vitaminas e minerais } \\
\text { voltados a conservação } \\
\text { da saúde e extensão da } \\
\text { jovialidade. }\end{array}$ \\
\hline $\begin{array}{l}\text { FERREIRA; } \\
\text { CAPOBIANCO } \\
(2016)\end{array}$ & $\begin{array}{l}\text { Relatar os benefícios } \\
\text { do Ácido } \\
\text { Hialurônico no } \\
\text { rejuvescimento } \\
\text { facial. }\end{array}$ & Revisão de literatura. & $\begin{array}{l}\text { O ácido hialurônico } \\
\text { ajuda na prevenção do } \\
\text { envelhecimento facial, } \\
\text { pois apresenta } \\
\text { propriedades }\end{array}$ \\
\hline
\end{tabular}




\begin{tabular}{|c|c|c|c|}
\hline & & & $\begin{array}{l}\text { antioxidantes, confere } \\
\text { volume, sustentação, } \\
\text { hidratação, e } \\
\text { elasticidade à pele, } \\
\text { melhorando assim, sua } \\
\text { estrutura e as linhas de } \\
\text { expressão. }\end{array}$ \\
\hline $\begin{array}{l}\text { SANTOS; } \\
\text { OLIVEIRA (2016) }\end{array}$ & $\begin{array}{l}\text { Estudar a ação das } \\
\text { vitaminas } \\
\text { antioxidantes no } \\
\text { envelhecimento } \\
\text { cutâneo precoce. }\end{array}$ & Revisão de literatura. & $\begin{array}{l}\text { A literatura sinaliza a } \\
\text { importância do } \\
\text { consumo alimentar } \\
\text { adequado como fator } \\
\text { para a prevenção do } \\
\text { envelhecimento da pele, } \\
\text { mas ela não sinaliza } \\
\text { doses estabelecidas e } \\
\text { recomendadas para esta } \\
\text { finalidade. }\end{array}$ \\
\hline ANDREATA (2017) & $\begin{array}{l}\text { Analisar o efeito de } \\
\text { rejuvenescimento } \\
\text { facial utilizando a } \\
\text { técnica de } \\
\text { Radiofrequência } \\
\text { juntamente com o } \\
\text { uso tópico de } \\
\text { vitamina C, aplicada } \\
\text { em mulheres na } \\
\text { faixa etária de } 45 \text { a } 60 \\
\text { anos. }\end{array}$ & Estudo de caso. & $\begin{array}{l}\text { Foi possível observar } \\
\text { benefícios quanto à } \\
\text { redução de rugas e } \\
\text { linhas de expressão, } \\
\text { bem como, melhora na } \\
\text { qualidade geral da pele. }\end{array}$ \\
\hline $\begin{array}{l}\text { GOMES; } \\
\text { MAGNUS;SOUZA } \\
(2017)\end{array}$ & $\begin{array}{l}\text { Elencar os principais } \\
\text { riscos e/ou } \\
\text { benefícios da } \\
\text { utilização destes } \\
\text { compostos visando } \\
\text { seu uso racional na } \\
\text { promoção da saúde. }\end{array}$ & Revisão de literatura. & $\begin{array}{l}\text { Os nutricosméticos } \\
\text { podem ser um } \\
\text { importante auxílio na } \\
\text { melhoria da qualidade } \\
\text { de vida, uma vez que } \\
\text { tais produtos oferecem } \\
\text { diversos benefícios à } \\
\text { saúde. }\end{array}$ \\
\hline $\begin{array}{l}\text { PINHEIRO; } \\
\text { SILVA; PESSOA } \\
(2018)\end{array}$ & $\begin{array}{l}\text { Analisar a inserção } \\
\text { dos nutricosméticos } \\
\text { nos cuidados } \\
\text { pessoais para o } \\
\text { tratamento da beleza } \\
\text { estética, baseado no } \\
\text { novo conceito de }\end{array}$ & Revisão de literatura. & $\begin{array}{l}\text { Os antioxidantes } \\
\text { também estão presentes } \\
\text { nos alimentos, } \\
\text { evidenciando assim a } \\
\text { importância da } \\
\text { alimentação correta e } \\
\text { balanceada para auxiliar }\end{array}$ \\
\hline
\end{tabular}




\begin{tabular}{|c|c|c|c|}
\hline & $\begin{array}{l}\text { beleza atual e que } \\
\text { traz benefícios para a } \\
\text { saúde do usuário. }\end{array}$ & & $\begin{array}{l}\text { no combate dos radicais } \\
\text { livres que causam o } \\
\text { envelhecimento. }\end{array}$ \\
\hline $\begin{array}{l}\text { SILVA; ALVES; } \\
\text { MORAES (2018) }\end{array}$ & $\begin{array}{l}\text { Analisar algumas } \\
\text { formulações } \\
\text { cosméticas } \\
\text { antienvelhecimento } \\
\text { que contenham as } \\
\text { vitaminas } \mathrm{A}, \mathrm{C} \text { e E, } \\
\text { quanto às suas } \\
\text { indicações, } \\
\text { benefícios e via de } \\
\text { administração, tópica } \\
\text { e oral. }\end{array}$ & Estudo de caso. & $\begin{array}{l}\text { Os produtos } \\
\text { cosméticos, por via oral } \\
\text { e tópica, devem ser } \\
\text { administrados } \\
\text { concomitantemente a } \\
\text { fim de somarem } \\
\text { esforços no tratamento } \\
\text { cutâneo, nutrindo e } \\
\text { tratando ao mesmo } \\
\text { tempo. }\end{array}$ \\
\hline $\begin{array}{l}\text { SALVADOR; } \\
\text { CECHINEL- } \\
\text { ZANCHETT(2018) }\end{array}$ & $\begin{array}{l}\text { Avaliar a relação do } \\
\text { consumo de } \\
\text { nutricosméticos na } \\
\text { prevenção e } \\
\text { tratamento das } \\
\text { desordens estéticas } \\
\text { selecionadas: acne e } \\
\text { envelhecimento } \\
\text { cutâneo. }\end{array}$ & Revisão de literatura. & $\begin{array}{l}\text { Os principais } \\
\text { nutricosméticos } \\
\text { evidenciados, foram } \\
\text { aqueles à base de } \\
\text { propriedades } \\
\text { antioxidantes. Todos } \\
\text { mostraram que os } \\
\text { efeitos antioxidantes } \\
\text { contribuem para } \\
\text { atenuar os sinais de } \\
\text { envelhecimento. }\end{array}$ \\
\hline $\begin{array}{l}\text { CÂNDIDO; } \\
\text { FORMOLO; } \\
\text { NICOLETTO } \\
(2020)\end{array}$ & $\begin{array}{l}\text { Avaliar o perfil de } \\
\text { pacientes que } \\
\text { frequentam o } \\
\text { Laboratório de } \\
\text { Estética da } \\
\text { Universidade de } \\
\text { Caxias do Sul, } \\
\text { quanto ao uso de } \\
\text { nutricosméticos. }\end{array}$ & $\begin{array}{l}\text { Estudo de caráter } \\
\text { epidemiológico. }\end{array}$ & $\begin{array}{l}\text { O perfil de pacientes } \\
\text { que frequentam os } \\
\text { laboratórios de Estética } \\
\text { e Cosmética da } \\
\text { Universidade de Caxias } \\
\text { do Sul quanto à } \\
\text { utilização de } \\
\text { nutricosméticos são } \\
\text { principalmente } \\
\text { mulheres de média } \\
\text { idade, que utilizam com } \\
\text { mais frequência o } \\
\text { nutricosmético de } \\
\text { vitamina D. }\end{array}$ \\
\hline $\begin{array}{l}\text { FERREIRA et } \\
\text { al.(2020) }\end{array}$ & $\begin{array}{l}\text { Verificar, por meio } \\
\text { de uma revisão de } \\
\text { literatura, se esse }\end{array}$ & Revisão de literatura. & $\begin{array}{l}\text { Os diversos tipos de } \\
\text { tratamentos para o } \\
\text { envelhecimento da pele }\end{array}$ \\
\hline
\end{tabular}




\begin{tabular}{|c|c|c|c|}
\hline & $\begin{array}{l}\text { tipo de tratamento é } \\
\text { uma boa opção de } \\
\text { escolha dentre os } \\
\text { vários métodos } \\
\text { existentes no } \\
\text { combate ao } \\
\text { envelhecimento } \\
\text { cutâneo por perda de } \\
\text { colágeno. }\end{array}$ & & $\begin{array}{l}\text { por perda de colágeno, } \\
\text { o uso do suplemento } \\
\text { oral na dieta apresenta- } \\
\text { se como uma boa opção } \\
\text { de escolha, uma vez que } \\
\text { vem apresentando } \\
\text { efeitos satisfatórios na } \\
\text { pele, permitindo uma } \\
\text { boa aparência e } \\
\text { aumentando a } \\
\text { autoestima da } \\
\text { população. }\end{array}$ \\
\hline $\begin{array}{l}\text { FREITAS et al. } \\
(2020)\end{array}$ & $\begin{array}{l}\text { Evidenciar a } \\
\text { importância dos } \\
\text { antioxidantes para a } \\
\text { prevenção contra a } \\
\text { ação dos radicais } \\
\text { livres no processo de } \\
\text { envelhecimento } \\
\text { cutâneo }\end{array}$ & Revisão de literatura. & $\begin{array}{l}\text { Foi evidenciado a } \\
\text { importância dos } \\
\text { antioxidantes para a } \\
\text { prevenção contra a ação } \\
\text { dos radicais livres no } \\
\text { processo de } \\
\text { envelhecimento } \\
\text { cutâneo, a fim de } \\
\text { amenizar os processos } \\
\text { oxidativos e minimizar } \\
\text { os danos causados nas } \\
\text { células. }\end{array}$ \\
\hline $\begin{array}{l}\text { PALADINI; } \\
\text { LOPES; } \\
\text { MACHADO (2020) }\end{array}$ & $\begin{array}{l}\text { Realizar uma revisão } \\
\text { bibliográfica } \\
\text { atualizada sobre o } \\
\text { resveratrol e seu uso } \\
\text { na prevenção do } \\
\text { envelhecimento } \\
\text { cutâneo. }\end{array}$ & Revisão de literatura. & $\begin{array}{l}\text { O resveratrol tem ação } \\
\text { antioxidante e é } \\
\text { ativador da sirtuína I, } \\
\text { que por sua vez, ativa } \\
\text { proteínas reparadoras } \\
\text { do DNA, podendo } \\
\text { assim ser auxiliar no } \\
\text { tratamento } \\
\text { antienvelhecimento. }\end{array}$ \\
\hline
\end{tabular}

Fonte: Dados da pesquisa, 2021.

O avanço biotecnológico, bem como a melhoria na qualidade de vida tem possibilitado que as pessoas alcancem estágios de desenvolvimento cada vez mais avançados no ciclo de vida e que o cenário atual revela que a indústria cosmética tem passado por um crescimento dinâmico, em virtude da busca cada vez maior por uma aparência mais jovem e saudável, que está relacionada com a melhora da qualidade de vida 
(FIGUEIREDO, 2011; ALVES et al. (2017).

Ferreira e Capobianco (2016) discutem em sua revisão que os nutricosméticos podem ser usados como um tratamento preventivo e curativo do envelhecimento cutâneo. Os nutricosméticos consistem em uma nova alternativa de produtos para a beleza, unindo os benefícios dos alimentos disponibilizados na dieta e dos cremes hidratantes, focados na prevenção dos sinais provocados pelo processo de envelhecimento (PAULA et al, 2017).

A literatura mostra que os Nutricosméticos consistem na união do conceito de alimento, fármaco e cosmético, e são prescritos para o tratamento da pele de dentro para fora, sem a associação de procedimentos invasivos. São suplementos que devem ser ingeridos por via oral, através de cápsulas, comprimidos ou sachês e possuem propriedades cosméticas de elementos nutricionais (PINHEIRO; SILVA; PESSOA, 2018).

Estes produtos estão disponíveis na apresentação de cápsulas, para o pronto consumo, possibilitando que os nutrientes sejam bem sintetizados e tenham uma ótima absorção. Contudo, é importante destacar que as cápsulas de nutricosméticos não tem papel de substituição dos alimentos, mas servir como aliados, sobretudo, para os indivíduos com dietas inadequadas e irregulares, de acordo as necessidades de cada pessoa (AGUIAR; OLIVEIRA; CARNIB, 2014).

De acordo com Alves e colaboradores (2017), apesar dos nutricosméticos serem produtos julgados como inovadores e terem confiabilidade testada por meio de estudos, não devem de forma alguma substituir a alimentação, visto que as fórmulas só podem incluir no máximo, cinco ou seis substâncias e que a prescrição destas suplementações pode variar conforme cada organismo.

Os nutricosméticos apresentam vantagens, em comparação aos cosméticos de uso tópico, porque beneficiam toda a estrutura da pele. Mas, entre as maiores vantagens associadas aos nutricomésticos está a possibilidade destes suplementos serem usados juntamente com os cosméticos que atuam via transdérmica (SILVA; ALVES; MORAES, 2018).

Os nutricosméticos atuam diretamente no ponto bioquímico relacionado com a sua ação, beneficiando os processos biológicos do organismo, por isso, os nutricosméticos podem ser considerados uma alternativa de complementação de nutrição. Para que haja 
bons resultados devem ser associados a atividade física e o cuidado com a pele, hidratação e fotoproteção (PEREIRA; CARDOSO, 2oI2; CÂNDIDO; FORMOLO; NICOLETTO, 2020).

No tocante aos elementos que compõe os nutricosméticos, Figueiredo (2011), Pereira e Cardoso (2012), Salles; Rodrigues; Coelho (2013), Alves et al. (2017), Pereira e Cardoso (2012), concordam que estes possuem elementos especiais tais quais: vitaminas, ácidos graxos essenciais, aminoácidos, minerais e outras substâncias antioxidantes com a capacidade de prevenir o envelhecimento, bem como entre outros benefícios, porque são produtos alimentares com ação cosmética, unindo à nutrição à saúde do corpo e da pele, haja vista, potencializarem os resultados para o tratamento da pele em associação com os produtos cosméticos de uso tópico.

Segundo Pinheiro; Silva; Pessoa (2018), os nutricosméticos são compostos por : vitaminas, ácidos graxos essenciais, aminoácidos, minerais e outras substâncias antioxidantes que previnem a queda capilar, o envelhecimento, entre outros benefícios e que consistem em produtos alimentares que exercem ação cosmética, unindo à nutrição à saúde do corpo e da pele e que as substâncias têm como objetivo potencializar os resultados para o tratamento da pele em associação com os produtos cosméticos de uso tópico e que os fatores que tem uma relação com a diminuição de beleza e com o envelhecimento podem ser beneficiados por combinações completas e concentradas de nutrientes, vitaminas, minerais e outros bioativos.

Os antioxidantes podem ser classificados como antioxidantes de prevenção, capazes de impedir a formação de radicais livres; antioxidantes varredores, que previnem o ataque de radicais livres às células; e de reparo, os quais removem os danos a molécula de DNA e reconstituem as membranas celulares deterioradas (FREITAS, et al., 2020).

O envelhecimento enfraquece as funções vitais do organismo e o envelhecimento cutâneo é somente uma parcela visível deste processo. Em virtude da principal causa deste fenômeno ser originada da formação de radicais livres, justifica-se a relevância dos suplementos alimentares administrados por via oral com função antioxidante, a exemplo de algumas vitaminas (PEREIRA; CARDOSO, 2012). Panzieira e colaboradores (20II) destacam que além de combater a produção exacerbada de radicais livres, os antioxidantes 
fortalecem as defesas naturais, protegendo o organismo dos danos causados pelos radicais livres.

Entretanto, os antioxidantes provenientes da dieta são indispensáveis contra oxidação e, sendo assim, se mostram com importante papel na manutenção da saúde, devido a prevenção de danos provocados pelos radicais livres, oferecendo o elétron ausente em suas moléculas, em que o radical livre estabiliza-se, não rompendo os elétrons de outras células (PEREIRA; CARDOSO, 2012; FREITAS et al. (2020).

O Ácido Hialurônico consiste em um dos ingredientes mais recentes introduzidos nos nutricosméticos, que possui uma ação hidratante, antioxidante, revitalizante e antirrugas. Este ativo encontra-se em maior quantidade na pele e ajuda na retenção do seu peso em água no interior das células da pele, sendo um ótimo hidratante. $\mathrm{Na}$ região da derme, ele é capaz de regular o balanço hídrico, a pressão osmótica, funcionando como um filtro estabilizando estruturas da pele por interações eletrostáticas, o que favorece o aumento da suavidade da pele e redução das rugas (FERREIRA; CAPOBIANCO, 2016; PALADINI; LOPES; MACHADO, 2020; FREITAS, 2020).

Outro componente bastante citado na literatura cientifica que trata sobre a temática é o colágeno, que consiste em uma proteína natural e um componente já presente na pele. O colágeno, concede a elastina e a queratina à pele a sua resistência, elasticidade e estrutura. $O$ corpo produz naturalmente o colágeno, no entanto, a produção é comprometida de forma gradual como parte do processo natural de envelhecimento. Os nutricosméticos contendo colágeno podem ajudar a melhorar o aspecto geral da pele, de modo a suavizar as linhas finas e as rugas, remove machas e aumenta a elasticidade da pele (CÂNDIDO; FORMOLO; NICOLETTO, 2020). Nos últimos anos, a indústria cosmética começou a produzir suplementos de colágeno oral, com a finalidade de ajudar a melhorar a aparência da pele, atenuar linhas finas e rugas, remover manchas e aumentar a firmeza da pele (FERREIRA et al., 2020).

Quanto aos nutricosméticos contendo a Vitaminas C, os estudos evidenciaram que são importantes neste tipo de suplemento, pois têm um elevado poder antioxidante, auxiliando no combate ao stress oxidativo, induzido pela radiação UV. A Suplementação de antioxidantes por via oral, entre eles a vitamina $C$, na fórmula de cápsulas, são 
consideradas potentes sequestradoras de radicais livres. A utilização da vitamina $\mathrm{C}$ tem despertado interesse devido às funções fisiológicas atribuídas a essa substância, consideradas como auxiliares na manutenção de uma pele jovem e saudável e na melhoria das características gerais da pele, atuando assim como um antioxidante aliado na prevenção do envelhecimento. Ainda como antioxidantes importantes, os carotenoides têm grande capacidade de desativar o oxigênio singleto e neutralizar radicais peroxil, reduzindo a cadeia de oxidação e que a vitamina $C$ é uma excelente doadora de elétrons, tem papel importante na formação do colágeno e na proteção da membrana contra a peroxidação lipídica (SALLES; RODRIGUES; COELHO, 2013).

Andreata (2017), verificou que a associação da técnica de radiofrequência com o uso tópico de vitamina $\mathrm{C}$, tem eficácia e pode ser considerada uma opção de tratamento para combater os sinais de envelhecimento, amenizando a flacidez cutânea e da redução de rugas e linhas de expressão, melhora na textura e na hidratação cutânea.

Sobre a vitamina $\mathrm{E}$, os estudos analisados mostraram que essa vitamina atua no organismo como um excelente antioxidante interruptor de cadeia que previne a propagação dos danos causados pelos radicais livres nas membranas biológicas e que o ácido ascórbico interfere no processo de biossíntese de colágeno e de elastina, haja vista possuir capacidade de promover cicatrização, e colaborar com o transporte de inúmeras substâncias por meio do sistema de vascularização (SANTOS E OLIVEIRA, 20i6; GOMES; MAGNUS; SOUZA , 2017).

A Vitamina E, ou tocoferol, age de modo a evitar o processo de peroxidação dos fosfolipídeos que estão presentes na membrana, que fazem a polimerização das células e que possui um importante papel, antioxidante, por doarem um átomo de hidrogênio e converterem os radicais livres em formas menos reativas e inofensivas, como papel como antioxidante, a vitamina $\mathrm{E}$ se associa a vários outros nutrientes, até mesmo com a vitamina A e vitamina $\mathrm{C}$, por meio do método de encapsulamento, o que proporciona compatibilidade entre ambas, além disso há uma dependência com o selênio, com a glutationa peroxidase de modo que esse complexo seja eficiente no enfretamento dos radicais livres (FERREIRA; CAPOBIANCO, 2016, SANTOS;OLIVEIRA, 2016) . 
No que concerne a vitamina $\mathrm{A}$, retinol e os carotenóides, estes estão presentes nas camadas epiderme e derme, e por participarem do processo de crescimento e diferenciação celular, são muito necessários para a saúde da pele (SILVA; FERREIRA, 2014).

Os retinoides participam da manutenção da integridade do epitélio e atuam por ligação a receptores nucleares, tais como: reparo do DNA, expressão gênica, estímulo ao crescimento e diferenciação de queratinócitos, melanócitos e fibroblastos, assim como produção da matriz extracelular pelos fibroblastos que a falta de vitamina A provoca a queratinização do epitélio ciliado mucossecretor e outras alterações epiteliais, a vitamina $\mathrm{A}$ vem sendo utilizada principalmente pelos seus precursores, os carotenoides, com ação próvitamínica, como excelentes antioxidantes e que uma vitamina muito bem absorvida pela pele, quando em uso tópico, atuando contra o espessamento e à pigmentação excessiva da pele, na diferenciação das células epiteliais e na síntese de colágeno, propiciando maciez e hidratação e combate contra os sinais do envelhecimento e que aliado ao uso da vitamina A tópica é importante associar uma suplementação, via oral, para reduzir o estresse oxidativo que as células da derme podem sofrer (COMINETTI; BORTOLI; ABDALLA; COZZOLINO (20II), GOMES; MAGNUS; SOUZA (2017), PALADINI; LOPES; MACHADO (2020).

Zinco e o cobre, por sua vez, são importantes antioxidantes e agem sobre os tecidos cutâneos. Em se tratando do zinco este tem a capacidade de promover a estimulação da síntese de citocinas de baixo potencial pró-inflamatório, inibindo a multiplicação de histamina, reduzindo desta maneira mudanças no DNA celular provocados pelos raios ultravioletas. No que diz respeito ao cobre, consiste em um integrante fundamental de inúmeras metaloenzimas, onde estão inclusos o citocromo-oxidase, lisil-oxidase superóxido dismutase e tirosinase (COMINETTI; BORTOLI; ABDALLA; COZZOLINO (20II), GOMES; MAGNUS; SOUZA (2017), FERREIRA et al., 2020).

Já luteína e licopeno são importantes agentes com ação anti-inflamatória e antioxidante e que a partir do estímulo à síntese das fibras colágenas, elásticas e de ácido hialurônico, infere-se que a associação seja capaz de interferir positivamente no processo de envelhecimento cutâneo, particularmente na manutenção das características de viscoelasticidade da derme, permitindo assim uma maior firmeza e elasticidade da pele, 
contribuindo para a melhora da estrutura de sustentação da derme e, em consequência, pode retardar o processo de envelhecimento cutâneo.

Os estudos discutiram que é necessário explicitar a existência de muitos desafios a serem superados no mercado de nutricosméticos, tais quais, a falta de conhecimento sobre os ingredientes/compostos ativos e os benefícios destes produtos fazendo com que os consumidores ainda não se sintam seguros em testar e aceitar os nutricosméticos, aliados ao ceticismo por parte dos consumidores nas alegações que estes produtos desempenhem algum resultado em relação à beleza e à saúde, devido a poucas evidências fornecidas pelos fabricantes dos produtos (ALVES; MORAES, 2018).

Os estudos aqui analisados evidenciaram os efeitos antioxidantes dos nutri cosméticos, vistos que este se mostraram capazes de atenuar os sinais de envelhecimento, seja causado por fotoexposição ou por oxidação celular. No entanto, alguns autores advertiram sobre a necessidade de mais pesquisas sobre o tema. Quanto aos desafios para a realização deste estudo, cita-se a deficiência ao acesso de alguns estudos, como estudos experimentais, além disso. No entanto, estas limitações não impossibilitam os achados que revelaram que os nutricosméticos combatem ao envelhecimento cutâneo causado pelo estresse oxidativo.

\section{CONSIDERAÇÕES FINAIS}

O uso dos nutricosméticos pode trazer benefícios como a melhora dos aspectos da pele e auxiliar no tratamento das disfunções da pele e tecidos em desordem. Deste modo, os nutricosméticos podem ser indicados de forma complementar nos tratamentos tanto estéticos quanto nutricionais e a suplementação diária é capaz de estimular a melhoria da pele, cabelo, unhas.

Nos estudos foi evidenciado que os nutricosméticos são suplementos nutricionais que apresentam na composição substâncias antioxidantes, que são capazes de reprimir a ação dos radicais livres e auxiliam no combate dos principais causadores do fotoenvelhecimento. Ademais, a presença de aminoácidos nestes compostos a melhora na hidratação cutânea, responsável pela sustentação da derme.

Os estudos apontaram que os antioxidantes como as vitaminas $\mathrm{A}, \mathrm{C}$ e $\mathrm{E}$, consistem na melhor forma de prevenir os efeitos deletérios dos radicais livres em excesso, 
porque as vitaminas agem de modo a inibir a ação destes radicais. Espera-se que possa ser expandido o conhecimento sobre os benefícios dos nutricosméticos no combate ao envelhecimento cutâneo, principalmente para profissionais farmacêuticos, esteticistas, e outros profissionais que despertam interesse nesta área. Além de se obter informações acerca dos riscos associados à sua utilização, a fim de alertar tanto usuários como profissionais prescritores.

\section{REFERÊNCIAS}

AGUIAR, Aglaine; OLIVEIRA, Bárbara Bruna Rodrigues; CARNIB, Lunna Paula. Efeito dos antioxidantes vitamina $\mathrm{C}$ e selênio em pacientes queimados: uma revisão bibliográfica. Sociedade Brasileira de Queimaduras Abril/Junho de 2014 Volume 13 | Número 2, v. 64014, p. 62, 2014.

ALVES, Hérick Hebert et al. Atuação do farmacêutico na saúde estética. Mostra Científica da Farmácia, v. 3, n. I, 2017.

ANDREATA, Maria Fernanda Garcia. Rejuvenescimento facial: a eficácia da radiofrequência associada à vitamina $C$. Estética e Bem Estar-Tubarão, 2017.

CÂNDIDO, Amanda Vieira; FORMOLO, Letícia; NICOLETTO, Bruna Bellincanta. Avaliação do perfil dos pacientes que frequentam os laboratórios de estética em relação ao uso de nutricosméticos. Saúde e meio ambiente: revista interdisciplinar, v. 9, p. 96-ı05, 2020.

COMINETTI, Cristiane et al. Considerações sobre estresse oxidativo, selênio e nutrigenética. Nutrire Rev. Soc. Bras. Aliment. Nutr, 201 .

CRUZ, Patricia et al. Nutrição e saúde dos cabelos: uma revisão. Advances in Nutritional Sciences, v. I, n. I, p. 33-40, 2020.

DIAS, Caroline Aparecida Rodrigues et al. A complexa interação entre radicais livres, suplementação e doenças. Revista Multidisciplinar das FIPMoc, n. Io, p. 34-43, 2011.

FERREIRA, Adriana Simões et al. Suplementação de colágeno e outras formas de 
tratamento no combate ao envelhecimento cutâneo. Revista Eletrônica Acervo Científico, v. 12, p. e4653-e4653, 2020.

FERREIRA, Natália Ribeiro; CAPOBIANCO, M. P. Uso do ácido hialurônico na prevenção do envelhecimento facial. Revista Cientifica UNILAGO, v. I, n. I, p. I-ıo, 2016.

FIGUEIREDO, F. Beleza de dentro para fora: conheça os nutricosméticos, uma nova categoria de produtos destinados à beleza.Revista Mundo Verde. Ano 4, Ed. 8, 201 .

FREITAS, Lorran Miranda Andrade et al. Antioxidantes como forma de prevenção contra a ação dos radicais livres no processo de envelhecimento cutâneo. ÚNICA Cadernos Acadêmicos, v. 3, n. I, 2020.

GOMES, Andréia Silva; MAGNUS, Karen; SOUZA, Alessandra Hübner. Riscos e Benefícios do uso de Nutracêuticos para a Promoção da Saúde. Revista Saúde e

Desenvolvimento, v. II, n. 9, p. 57-75, 2017.

KING. Nutricosmetics: A Global Strategic Business Report [Em linha]. Disponível em 〈http://www.companiesandmarkets.com/News/Consumer-Goods/Nutricosmetics-AGlobal-Strategic-Business-Report/NI2548>.

OLIVEIRA, Andressa Costa et al. Efeitos do ácido ascórbico no combate ao envelhecimento cutâneo. BWS Journal, v. I, p. I-7, 2018.

PALADINI, Andreia Medeiros; LOPES, Talita Durante; MACHADO, Karina Elisa. Benefícios do resveratrol como ativo cosmético na prevenção do envelhecimento cutâneo. Infarma-Ciências Farmacêuticas, v. 32, n. 4, p. 319-328, 2020.

PEIXOTO, Fernanda Marques et al. Teor de carotenoides em nutricosméticos: análise da adequação e qualidade do produto. Revista do Instituto Adolfo Lutz, v. 72, n. 3, p. 249-254, 2013.

PEREIRA, Renata Junqueira; CARDOSO, Maria. Metabólitos secundários vegetais e benefícios antioxidantes. Journal of biotechnology and biodiversity, v. 3, n. 4, 2012.

PINHEIRO, Ermeson Olavo Pereira; SILVA, Carlos Wendel Viana; PESSOA, Cinara 
Vidal. Nutricosméticos: um novo conceito de beleza. Mostra Científica da Farmácia, v. 4, n. 2, 2018.

SALLES, Bruna dos Santos; RODRIGUES, Bruna Lauria; COELHO, Simone Côrtes. A importância do zinco na desnutrição humana e seus benefícios na infância. Rev Bras Nutr Clin, v. 28, n. 3, p. 245-50, 2013.

SALVADOR, Maitê Mascarello Giotti; CECHINEL-ZANCHETT, Camile Cecconi. Nutricosméticos em desordens estéticas: foco na acne e envelhecimento cutâneo. ARCHIVES OF HEALTH INVESTIGATION, v. 8, n. I2, 2019.

SANTOS, José Alberto Fernandes Gomes dos. Exercício físico, radicais livres, espécies reativas de oxigênio, envelhecimento e doenças neurodegenerativas. 2017.

SANTOS, Mirelli Papalia; OLIVEIRA, Nádia Rosana Fernandes. Ação das vitaminas antioxidantes na prevenção do envelhecimento cutâneo. Disciplinarum Scientia| Saúde, v. I5, n. I, p. 75-89, 2016.

SILVA, Beatriz da Conceição Cabral. Segurança e eficácia de Cosmecêuticos e Nutracêuticos utilizados na prevenção e retardamento do fotoenvelhecimento da pele. 2015 . Tese de Doutorado

SILVA, Ellen Cristyne Teodoro Ferreira; ALVES, Mariana Rocha Sales; MORAES, Anamaria Junqueira. Utilização das vitaminas "A", "C" "E” em produtos cosméticos antienvelhecimento de uso oral e tópico. e-RAC, v. 8, n. I, 2018.

SILVA, Luiz Fernando Miranda da; FERREIRA, Karla Silva. Food safety of supplements sold in Brazil. Revista Brasileira de Medicina do Esporte, v. 20, n. 5, p. 374-378, 2014. 